\title{
Factors Affecting the Degree of Angular Remodeling in Stent-Assisted Coiling of Bifurcation Aneurysms
}

\author{
Ahmed Saied $^{a}$ b Nada Elsaid ${ }^{a, b} \quad$ Krishna Joshi $^{a} \quad$ Mohamed Gomaa $^{b}$ \\ Talal Amer ${ }^{c}$ Mohamed Saad $^{b}$ Demetrius Lopes ${ }^{d}$ \\ ${ }^{a}$ Department of Neurological Surgery, Rush University Medical Center, Chicago, IL, USA; \\ ${ }^{\mathrm{b}}$ Department of Neurology, Mansoura University, Mansoura, Egypt; ${ }^{\mathrm{C}}$ Department of \\ Radiology, Mansoura University, Mansoura, Egypt; ${ }^{d}$ Advocate Aurora Health, Aurora, CO, \\ USA
}

\section{Keywords}

Recanalization · Bifurcation aneurysm · Stent-assisted coiling · Angular remodeling

\begin{abstract}
Background: Stent-assisted coiling (SAC) leads to significant changes in the vascular angle altering the bifurcation geometry and the hemodynamics at the bifurcation apex. It is believed that the stent alone exerts this effect, but other possible factors have not been studied. Purpose: To study the factors contributing to angular remodeling following SAC of bifurcation aneurysms including the anatomical, stent-related, and coil-related factors. Materials and Methods: We reviewed 43 basilar and carotid bifurcation aneurysms treated by SAC using Neuroform EZ $(n=28)$, Enterprise $(n=8)$, and Lvis Jr. $(n=7)$ stents. The bifurcation angle between the mother and stented daughter vessel was measured in 4 settings: pretreatment, poststenting, postcoiling, and at delayed follow-up (6-12 months). The degree of stent-induced angular remodeling was calculated by subtracting the poststenting bifurcation angle from the pretreatment one, while the coil-induced angular remodeling was calculated as the difference between the postcoiling and poststenting bifurcation angle. The immediate postprocedural degree of angular remodeling is the sum of the stent- and coil-induced angular remodeling. We studied the effect of several factors including the pretreatment bifurcation angle, aneurysm site, diameter of parent vessel, stent type, stent length in the daughter vessel, postoperative actual in situ coil size, and packing density. Results: The mean degree of stent-induced and coil-induced angular remodeling was 10.2 (0-47) and 4.53 (-7 to 30), respectively. The immediate postprocedural and delayed angular remodeling was 14.8 ( -4 to $47)$ and 4.75 ( -12 to 40$)$, respectively. The degree of immediate remodeling was significantly
\end{abstract}


affected by the actual in situ coil size $(p=0.017)$, and the pretreatment bifurcation angle $(p=$ $0.024)$. Linear regression was carried out and the pretreatment bifurcation angle was defined as a predictor. The degree of delayed remodeling is significantly affected only by the pretreatment bifurcation angle $(p=0.011)$. Conclusion: Immediate angular remodeling following SAC of bifurcation aneurysms can happen after stenting or coiling or both. This is the first study reporting the role of the coils as an additional factor beside the stent in inducing immediate angular changes; this effect is correlated to the size of the coils. The pretreatment bifurcation angle is the most consistent factor affecting the degree of both immediate and delayed angular remodeling.

(c) 2019 S. Karger AG, Basel

\section{Introduction}

Stent-assisted coiling (SAC) represents the mainstay of the treatment of bifurcation aneurysms especially those with a wide neck and a low dome-to-neck ratio. Besides its mechanical scaffolding effect, which secures the coils from prolapse and allows a higher packing density and direct reduction of flow by the stent struts, it leads to significant changes in the vascular angle, altering the bifurcation geometry and changing the hemodynamics at the bifurcation apex [1]. The results of computational flow and ideal aneurysm model analysis also suggest that this angular remodeling is associated with favorable outcomes [2, 3], as it leads to a lower pressure, inflow volume rate, and inflow velocity in the aneurysm [2-4].

The biphasic nature of angular remodeling (immediate and delayed) has been repeatedly reported and is attributed to the stent's self-expanding effect that results in an effective straightening of the stented vessel segment, termed stent-induced immediate and delayed angular remodeling $[1,5-8]$. No data are available on whether other factors contribute to the degree of angular remodeling besides the stent effect.

Our aim is to study the possible effects of various factors on the degree of angular remodeling in the SAC of bifurcation aneurysms including the anatomical, stent-related, and coilrelated factors.

\section{Materials and Methods}

We reviewed 43 basilar and carotid bifurcation aneurysms treated by SAC using Neuroform EZ ( $n=28)$, Enterprise ( $n=8)$, and Lvis Jr. ( $n=7)$ stents. Not all patients were eligible for simple coiling due to the large size of the aneurysm, the wide neck, or the bifurcation configuration. In all of the included cases, either the "jailing" or "coil through" technique was used. The bifurcation angle is the angle formed between the intersection of the center lines of the parent artery and the stented daughter branch (Fig. 1) [1-4]. As the ability to measure angles accurately in a 2-dimensional (2-D) view of a 3-D process can be difficult and the placement of a line through the center axis of a vessel may result in a change in angle, 3 experienced observers measured the angle and the mean value of the measured angles was calculated and recorded. It was measured in 4 settings from the same working angle: pretreatment, poststenting, postcoiling, and at a delayed follow-up (6-12 months). The degree of stent-induced angular remodeling was calculated by subtracting the poststenting bifurcation angle from the pretreatment one, while the coil-induced angular remodeling was calculated as the difference between the postcoiling and poststenting bifurcation angle. The immediate postprocedural degree of angular remodeling is the sum of the stent- and coil-induced angular remodeling.

We categorized the possible influencing factors into 3 main domains:

1 Anatomical, including the aneurysm site, diameter of the parent vessel, and pretreatment bifurcation angle

2 Stent-related, including the stent type and the length of the stent in the daughter vessel

3 Coil-related, including the postoperative actual in situ coil size and packing density. 
Saied et al.: Factors Contributing to Angular Remodeling in SAC of Bifurcation Aneurysms

Fig. 1. Method of measuring the bifurcation angle.

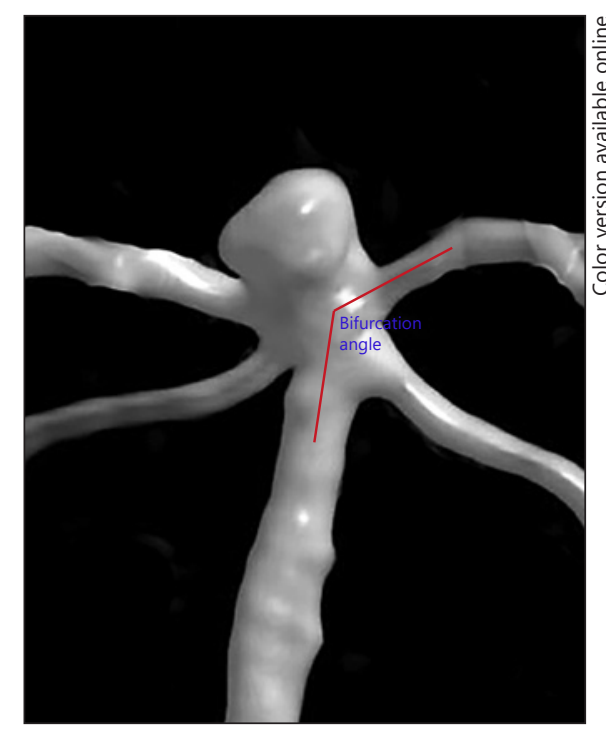

Statistical Analysis

Data were statistically analyzed using SPSS v21 (IBM Corp., Armonk, NY, USA). Differences were analyzed using the two-tailed Mann Whitney U test. Comparisons of $\geq 3$ groups were analyzed by KruskalWallis test. All correlations were made by Spearman correlation. Linear regression was carried out to detect the predictors of immediate remodeling. $p \leq 0.05$ was considered statistically significant.

\section{Results}

\section{Anatomical Factors}

There were 43 incidentally discovered intracranial bifurcation aneurysms, 24 of which $(55.8 \%)$ at the basilar tip and $19(44.2 \%)$ at the carotid terminus were treated by elective single SAC (Table 1).

The parent vessel diameter ranged between 1.8 and $3.2 \mathrm{~mm}$ with a mean of $2.62 \pm 0.36$ $\mathrm{mm}$.

Neither the aneurysm site nor the diameter of the parent vessel statistically affected the degree of immediate or delayed angular remodeling.

The mean degree of the pretreatment bifurcation angle ranged between $122^{\circ}$ and $230^{\circ}$ with a mean of $174^{\circ}$. The pretreatment bifurcation angle significantly affected both the immediate and delayed degrees of angular remodeling ( $p=0.024$ and $p=0.011$, respectively) (Table 1 ).

\section{Stent-Related Factors}

The stent deployment changed the degree of the bifurcation angle in 40 aneurysms. The mean degree of stent-induced angular remodeling was 10.2 (0-47). This change was exclusively related to the stent deployment in 22 cases and was further modified after coil deployment in 18 cases. The types of stents used were Neuroform EZ $(n=28)$, Enterprise $(n=8)$, and Lvis Jr. $(n=7)$. Stent-induced angular remodeling was observed at a higher degree with stiffer closed-cell Enterprise stents than with open-cell Neuroform EZ stents, with a mean of $45.0^{\circ}$ and $15.0^{\circ}$, respectively, but no statistically significant difference. The mean length of the stent arm in the daughter vessel at which it was deployed was $9.53 \mathrm{~mm}$. Neither the stent type nor the stent length in the daughter vessel affected the degree of angular remodeling in the immediate or delayed setting (Table 2). 
Table 1. Characteristics of the study subjects

\begin{tabular}{|c|c|}
\hline & $n=43$ \\
\hline \multicolumn{2}{|l|}{ Demographic and clinical data } \\
\hline Age, years & $59(37-79)$ \\
\hline \multicolumn{2}{|l|}{ Gender } \\
\hline Male & $18(41.9)$ \\
\hline Female & $25(58.1)$ \\
\hline Hypertension & 27 (62.8) \\
\hline Smoking & $16(37.2)$ \\
\hline Alcohol drinking & $17(39.5)$ \\
\hline \multicolumn{2}{|l|}{ Pretreatment geometric data } \\
\hline \multicolumn{2}{|l|}{ Site } \\
\hline Basilar & $24(55.6)$ \\
\hline Carotid & $19(44.4)$ \\
\hline Size, $\mathrm{mm}$ & $6.55(1.5-16.5)$ \\
\hline Neck size, mm & $5.07(1.6-8.4)$ \\
\hline Aspect ratio & $1.53(0.6-2.6)$ \\
\hline Dome-to-neck ratio & $1.4(0.7-3.0)$ \\
\hline \multicolumn{2}{|l|}{ Treatment-related factors } \\
\hline \multicolumn{2}{|l|}{ Initial ROS } \\
\hline Complete occlusion & $26(60.4)$ \\
\hline Residual neck & $12(28)$ \\
\hline Body filling & $5(11.6)$ \\
\hline Packing density, range (mean \pm SD) $(n=29)$ & $12-69(30.14 \pm 13.52)$ \\
\hline \multicolumn{2}{|l|}{ Stent type } \\
\hline Neuroform EZ & $28(65.1)$ \\
\hline Enterprise & $8(18.6)$ \\
\hline Lvis Jr. & $7(16.2)$ \\
\hline \multicolumn{2}{|l|}{ Radiological outcome } \\
\hline Recanalization & $7(16.3)$ \\
\hline
\end{tabular}

Values are expressed as $n(\%)$ or median (range), unless otherwise indicated. ROS, reactive oxygen species.

\section{Coil-Induced Factors}

Coil deployment only induced changes in the degree of the bifurcation angle in 3 cases and further changes to those previously induced by stent deployment in 18 cases. The mean degree of coil-induced angular remodeling was 4.53 ( -7 to 30$)$. The actual coil size was measured after the coil deployment within the aneurysm. It ranged from 1.5 to $16.5 \mathrm{~mm}$ with a mean value of $6 \mathrm{~mm}$, noting that the median aneurysm size was $5 \mathrm{~mm}$ (range 1.4-17.4 mm). The actual coil size significantly influenced the degree of angular remodeling $(r=0.363, p=$ 0.017 ). Actual coil size of $\leq 3 \mathrm{~mm}$ did not induce any immediate angular change. The packing density could be obtained only in 29 cases with a mean of $30.14 \%$ and did not statistically affect the degree of immediate or delayed angular remodeling (Table 3).

\section{Degree of Angular Remodeling}

The mean degree of the immediate postprocedural angular remodeling was 14.8 ( -4 to 47 ), and that of the delayed angular remodeling was 4.75 (-12 to 40). The degree of immediate remodeling was significantly affected by the actual in situ coil size $(p=0.017)$ and pretreatment bifurcation angle $(p=0.024)$. Multivariate analysis and linear regression were carried out and the pretreatment bifurcation angle was defined as a predictor of the degree 
Saied et al.: Factors Contributing to Angular Remodeling in SAC of Bifurcation Aneurysms

Table 2. The contribution of anatomical factors to the degree of angular remodeling

\begin{tabular}{lllll}
\hline & $\begin{array}{l}\text { Stent-induced } \\
\text { angular } \\
\text { remodeling }\end{array}$ & $\begin{array}{l}\text { Coil-induced } \\
\text { angular } \\
\text { remodeling }\end{array}$ & $\begin{array}{l}\text { Immediate } \\
\text { (postprocedural) } \\
\text { angular remodeling }\end{array}$ & $\begin{array}{l}\text { Delayed } \\
\text { angular } \\
\text { remodeling }\end{array}$ \\
\hline $\begin{array}{l}\text { Parent vessel diameter } \\
r\end{array}$ & -0.095 & -0.200 & -0.004 & 0.167 \\
$p$ & 0.549 & 0.205 & 0.980 & 0.309 \\
\hline $\begin{array}{l}\text { Pretreatment bifurcation angle }{ }^{\mathrm{b}} \\
r\end{array}$ & 0.149 & 0.010 & -0.343 & 0.397 \\
$p$ & 0.340 & 0.951 & 0.024 & 0.011 \\
\hline a Range: $1.8-3.2$ and mean \pm SD: $2.62 \pm 0.36$. & & & \\
${ }^{\mathrm{b}}$ Median (range): 174 (122-230). & & & \\
\hline
\end{tabular}

Table 3. The contribution of stent-related factors to the degree of angular remodeling

\begin{tabular}{|c|c|c|c|c|}
\hline & $\begin{array}{l}\text { Stent-induced } \\
\text { angular } \\
\text { remodeling }\end{array}$ & $\begin{array}{l}\text { Coil-induced } \\
\text { angular } \\
\text { remodeling }\end{array}$ & $\begin{array}{l}\text { Immediate } \\
\text { (postprocedural) } \\
\text { angular } \\
\text { remodeling }\end{array}$ & $\begin{array}{l}\text { Delayed } \\
\text { angular } \\
\text { remod- } \\
\text { eling }\end{array}$ \\
\hline \multicolumn{5}{|l|}{ Stent type } \\
\hline$r$ & -0.164 & -0.022 & -0.069 & 0.137 \\
\hline$p$ & 0.292 & 0.889 & 0.659 & 0.401 \\
\hline \multicolumn{5}{|c|}{ Stent length in the daughter vessel ${ }^{\mathrm{a}}$} \\
\hline$r$ & -0.235 & 0.038 & 0.134 & -0.094 \\
\hline$p$ & 0.196 & 0.836 & 0.466 & 0.627 \\
\hline Stent type & $\begin{array}{l}\text { Degree of angular } \\
\text { remodeling }\end{array}$ & Kruskal-Wallis test & & \\
\hline Neuroform EZ $(n=28)$ & $15.0(0.0-45.0)$ & $p=0.41$ & & \\
\hline Enterprise $(n=8)$ & $45.0(0.0-47.0)$ & & & \\
\hline Lvis Jr. $(n=7)$ & $24.0(19.0-29.0)$ & & & \\
\hline
\end{tabular}

of immediate remodeling (Table 4). The degree of delayed remodeling was significantly affected only by the pretreatment bifurcation angle $(p=0.011)$. Neither the degree of stent-or coil-induced angular remodeling correlated with the degree of immediate or delayed remodeling (Table 5). Also, the degree of immediate angular remodeling did not affect that of the delayed angular remodeling $(r=-0.122, p=0.453)$.

\section{Radiological Outcome}

Immediate occlusion was achieved in $88.4 \%$, and in $90.7 \%$ at latest follow-up with average follow-up time of 14 months. Seven aneurysms (16.3\%) showed recanalization (further filling of the aneurysm neck or sac was observed compared with the initial treatment findings). There was no statistically significant difference between the recanalized and non-recanalized groups regarding the degree of the immediate or delayed angular remodeling (Table 6).

A subanalysis of the carotid and bifurcation aneurysms showed no statistically significant difference between them regarding pretreatment related factors, treatment-related factors, or the degree of angular remodeling (Table 7). 
Saied et al.: Factors Contributing to Angular Remodeling in SAC of Bifurcation Aneurysms

Table 4. The contribution of coil-related factors to the degree of angular remodeling

\begin{tabular}{llllr}
\hline & $\begin{array}{l}\text { Stent-induced } \\
\text { angular } \\
\text { remodeling }\end{array}$ & $\begin{array}{l}\text { Coil-induced } \\
\text { angular } \\
\text { remodeling }\end{array}$ & $\begin{array}{l}\text { Immediate } \\
\text { (postprocedural) } \\
\text { angular } \\
\text { remodeling }\end{array}$ & $\begin{array}{l}\text { Delayed } \\
\text { angular } \\
\text { remodeling }\end{array}$ \\
\hline $\begin{array}{l}\text { Postoperative actual coil size } \\
r\end{array}$ & -0.035 & -0.036 & 0.363 & -0.142 \\
$p$ & 0.823 & 0.820 & 0.017 & 0.381 \\
\hline $\begin{array}{l}\text { Packing density } \\
r\end{array}$ & -0.126 & -0.029 & 0.249 & -0.116 \\
$p$ & 0.905 & 0.756 & 0.276 & 0.714 \\
\hline a Range: $1.5-16.5$ and mean \pm SD: $6 \pm 3$. & & & \\
$\quad$ b Range: $12-69$ and mean \pm SD: $30.14 \pm 13.52$. & & & \\
\hline
\end{tabular}

Table 5. Multivariate analysis of the factors affecting the immediate angular remodeling

\begin{tabular}{lllrr}
\hline & \multicolumn{2}{l}{ Unstandardized coefficients } & \multirow{2}{*}{$t$} & $p$ value \\
\cline { 2 - 4 } & $\beta$ & standard error & & \\
\hline (Constant) & 32.836 & 8.137 & 4.035 & $<0.001$ \\
Pretreatment angle & -0.176 & 0.069 & -2.546 & 0.015 \\
Postoperative coil size & 0.000 & 0.536 & -0.002 & 0.999 \\
\hline
\end{tabular}

$R^{2}=0.14$

Table 6. Univariate analysis of the stent-induced and coilinduced effects on postprocedural (immediate and delayed) angular remodeling

\begin{tabular}{lll}
\hline Effects & $\begin{array}{l}\text { Immediate angular } \\
\text { remodeling }\end{array}$ & $\begin{array}{l}\text { Delayed angular } \\
\text { remodeling }\end{array}$ \\
\hline Stent-induced & & \\
$r$ & 0.037 & 0.185 \\
$p$ & 0.813 & 0.254 \\
\hline Coil-induced & & \\
$r$ & -0.105 & -0.038 \\
$p$ & 0.501 & 0.818 \\
\hline
\end{tabular}

\section{Discussion}

The factors affecting the degree of angular remodeling after the SAC of bifurcation aneurysms can be divided into anatomical, stent-related, and coil-related.

\section{Anatomical Factors}

Aneurysm Site and Parent Vessel Diameter

The degree of the immediate angular remodeling was greater in the basilar group than in the carotid group, but this difference was not statistically significant. The diameter of the parent vessel did not statistically affect the degree of the angular remodeling. Previous studies reported angular remodeling in a descending manner in the anterior communicating artery, 


\section{Interventional Neurology}

\begin{tabular}{l|l}
\hline \multicolumn{2}{l|}{ Intervent Neurol 2019;8:220-230 } \\
\hline DOI: 10.1159/000502058 & $\begin{array}{l}\text { (c) 2019 S. Karger AG, Basel } \\
\text { www.karger.com/ine }\end{array}$ \\
\hline
\end{tabular}

Saied et al.: Factors Contributing to Angular Remodeling in SAC of Bifurcation Aneurysms

Table 7. Subanalysis of basilar and carotid aneurysms

\begin{tabular}{|c|c|c|c|}
\hline & $\begin{array}{l}\text { Basilar } \\
(n=24)\end{array}$ & $\begin{array}{l}\text { Carotid } \\
(n=19)\end{array}$ & $p$ value \\
\hline \multicolumn{4}{|l|}{ Demographic and clinical data } \\
\hline Age, years & $63.9(44-79)$ & $60(37-76)$ & 0.61 \\
\hline \multicolumn{4}{|l|}{ Gender } \\
\hline Male & $9(37.5)$ & $9(47.4)$ & 0.45 \\
\hline Female & $15(62.5)$ & $10(52.6)$ & \\
\hline Hypertension & $16(66.6)$ & $11(57.9)$ & 1.8 \\
\hline Smoking & $11(45.8)$ & $5(26.3)$ & 0.2 \\
\hline Alcohol drinking & $9(37.5)$ & $8(42.1)$ & 0.12 \\
\hline \multicolumn{4}{|l|}{ Pretreatment geometric data } \\
\hline Size, mm & $7.9(1.5-16.5)$ & $7.18(2.1-16.4)$ & 0.18 \\
\hline Neck size, $\mathrm{mm}$ & $3.8(1.6-8.4)$ & $4.9(4.4-6.7)$ & 0.13 \\
\hline Aspect ratio & $1.1(0.6-2.6)$ & $1.63(0.9-2.2)$ & 0.26 \\
\hline Dome-to-neck ratio & $1.7(1.3-3.0)$ & $1.1(0.7-2.7)$ & 0.07 \\
\hline Parent vessel diameter, $\mathrm{mm}$ & $2.5(1.8-3.0)$ & $2.68(2-3.2)$ & 0.15 \\
\hline Pretreatment bifurcation angle, degrees & $170.62(130-224)$ & $175.24(122-230)$ & 0.46 \\
\hline \multicolumn{4}{|l|}{ Treatment-related factors } \\
\hline \multicolumn{4}{|l|}{ Initial ROS } \\
\hline Complete occlusion & $14(58.33)$ & $12(63.1)$ & 0.13 \\
\hline Residual neck & $7(29.16)$ & $5(26.3)$ & \\
\hline Body filling & $3(12.5)$ & $2(10.5)$ & \\
\hline Packing density & $27.38(12-69)$ & $21.31(14-58)$ & 0.11 \\
\hline \multicolumn{4}{|l|}{ Stent type } \\
\hline Neuroform EZ & $16(66.6)$ & $12(63.1)$ & 0.23 \\
\hline Enterprise & $4(16.7)$ & $4(21.1)$ & \\
\hline Lvis Jr. & $4(16.7)$ & $3(15.8)$ & \\
\hline Postoperative actual coil size, $\mathrm{mm}$ & $6.3(1.5-16.5)$ & $7.18(2.1-16.4)$ & 0.29 \\
\hline Stent length in the daughter vessel, $\mathrm{mm}$ & $9.5(6-15)$ & $8.8(4-14)$ & 0.45 \\
\hline \multicolumn{4}{|l|}{ Degree of angular remodeling } \\
\hline Stent-induced & $9.5(2-47)$ & $10.3(0-45)$ & 0.32 \\
\hline Coil-induced & $4.1(3-30)$ & $4.42(-7$ to 28$)$ & 0.19 \\
\hline Immediate postprocedural & $13.8(6-74)$ & $14.5(-4$ to 45$)$ & 0.22 \\
\hline Delayed & $12.5(9-40)$ & $3.7(-12$ to 38$)$ & 0.28 \\
\hline
\end{tabular}

Values are expressed as $n(\%)$ or median (range). ROS, reactive oxygen species.

middle cerebral artery, basilar, and carotid bifurcations, respectively, contrary to the order of the vessel caliber at these locations. This finding suggests that the greater the vessel size, the greater the resistance of the vessel against the straightening force exerted by the bent stent $[6,9]$. Other studies failed to report this inverse relationship between the parent vessel diameter and degree of angular change $[1,6]$.

Pretreatment Angle

The pretreatment bifurcation angle significantly affected both the immediate $(p=0.024)$ and delayed $(p=0.011)$ angular remodeling and was defined as a predictor of the degree of immediate remodeling ( $p=0.015)$ in the multivariate analysis. There was an inverse relationship between the pretreatment bifurcation angle and the degree of angular remodeling $(r=-0.343)$. This was previously suggested as a higher degree of angular remodeling was observed with narrow angles than with wider angles. The smaller the presenting vascular 
Saied et al.: Factors Contributing to Angular Remodeling in SAC of Bifurcation Aneurysms
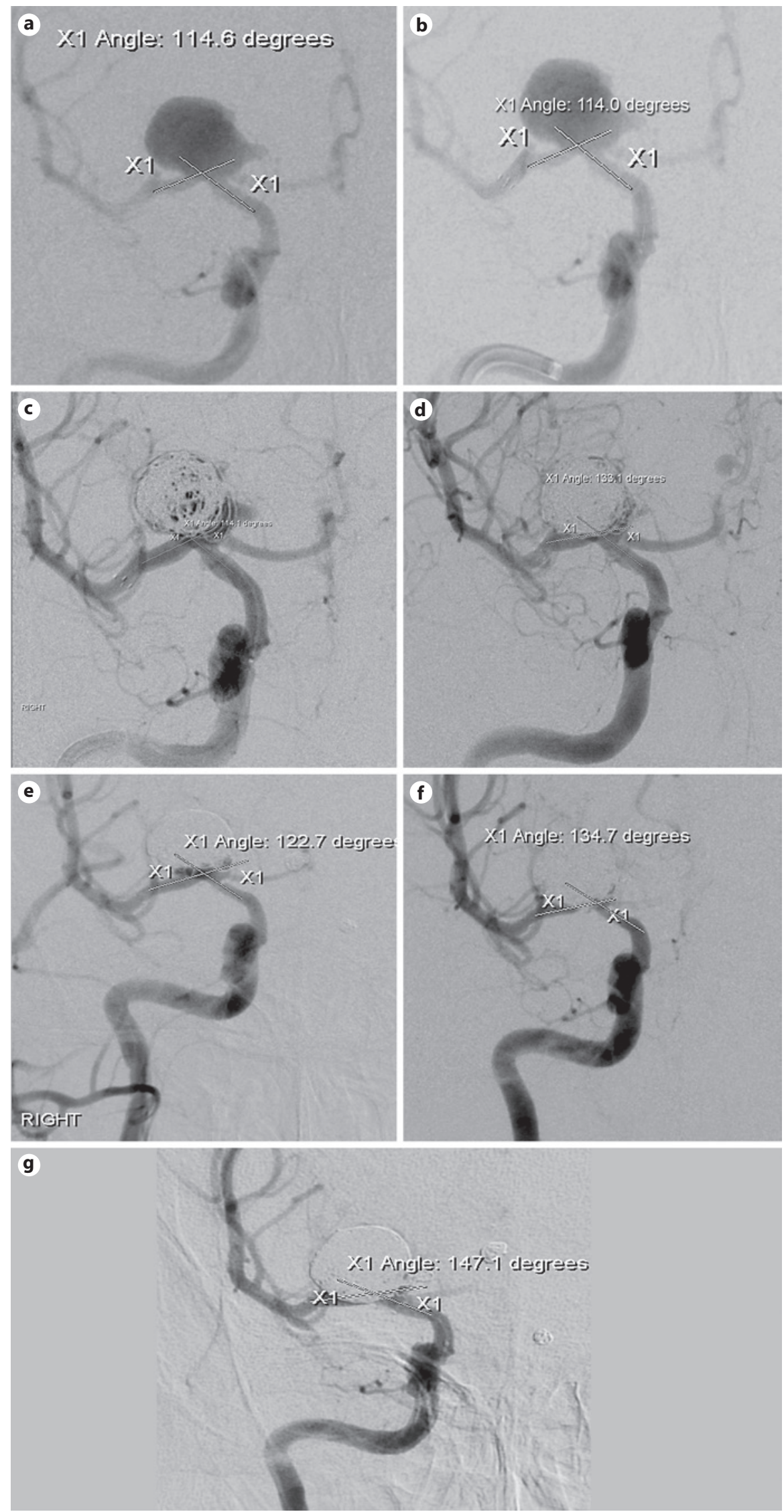
angle, the greater is the deformation of the stent and its bending angle, and, consequently, the greater is the straightening force of the stent, which then causes a greater angular modification following stent placement $[5,6,9]$.

\section{Stent-Related Factors}

Stent Type

A higher degree of angular remodeling was observed with the closed-cell Enterprise stent than with the open-cell Neuroform EZ stent, with a mean degree of 45 and 15, respectively. The closed-cell design makes the stent work as a whole body which has a greater longitudinal stiffness and a greater reactive force to bending, immediately transmitting a force used at one end to the other end $[10,11]$. This leads to effective straightening of the curved vessel in which the stent is implemented $[1,6,10,11]$. Stents with an open-cell design show significantly less angular remodeling $[1,6]$.

\section{Stent Length in the Daughter Branch}

We studied the length of the stent in the stented daughter vessel as this may affect the degree of angular remodeling by influencing the distribution of the force on the resistance of the long vascular wall. Our results showed that the length of the stent in the daughter vessel did not statistically affect the degree of the angular remodeling either in immediate or delayed angular remodeling.

\section{Coil-Related Factors}

It was thought that the stent only is responsible for angular remodeling. We observed that the immediate angular remodeling may happen after stent deployment only, after coiling only, or after both, in a complementary manner, suggesting the important role of the coils in the remodeling process.

\section{Coil Size}

Actual coil size showed a significant correlation with the degree of immediate angular remodeling ( $p=0.017)$. The larger the coil size, the greater the degree of the immediate angular remodeling. This effect may be mediated by the compressive effect of the coils on the angulated part of the stent, favoring its straightening. This may be supported by the fact that coils of $\leq 3 \mathrm{~mm}$ did not contribute to the immediate angular remodeling.

\section{Packing Density}

The packing density did not statistically affect the degree of immediate or delayed angular remodeling, but it must be noted that we were able to obtain this value in only 29 cases.

\section{Coil Compaction}

In some cases, where the coils were compacted on follow-up, we observed bending of previously straightened stents with a loss of the coil-induced angular remodeling, as shown in the following case (Fig. 2).

Fig. 2. a An internal carotid artery terminus aneurysm before treatment. No change was observed in the pretreatment bifurcation angle upon stent deployment (b) or early coiling (c). d Immediate angular remodeling was observed upon completion of coiling. e Coil compaction observed at the 6-month follow-up was associated with the loss of a certain degree of angular remodeling. $\mathbf{f}$ Upon retreatment by coiling, the bifurcation angle regained the lost degree of angular remodeling. $\mathbf{g}$ At the 1-year follow-up, the bifurcation angle showed progression of the angular remodeling, called delayed angular remodeling. 
During the initial treatment of the carotid bifurcation aneurysm, immediate angular remodeling was observed after completion of coiling, but not with initial coiling or stent deployment. Interestingly, coil compaction was observed at the 6-month follow-up and was associated with the loss of a certain degree of the angular remodeling. On retreatment by coiling, the stent regained the lost remodeling observed at the previous follow-up. At the 1-year follow-up, the bifurcation angle showed progression of the angular remodeling, called "delayed angular remodeling."

The effect of the angular remodeling on radiological outcome has still not been established, but, as mentioned before, the results of computational flow and ideal aneurysm model analysis suggest that it is associated with favorable outcomes [2, 3], as it leads to lower pressure, inflow volume rate, and inflow velocity in the aneurysm. Further larger studies are needed to examine the possible contribution to the radiological outcome of the hemodynamic changes induced by the angular remodeling.

\section{Conclusion}

Immediate angular remodeling following SAC of bifurcation aneurysms can happen after stenting or coiling or both. For a long time, it was thought that the stent alone is responsible for the angular remodeling in SAC. This is the first study reporting the role of the coils as an additional factor to the stent in inducing the immediate angular changes; this effect is correlated to the size of the coils. The pretreatment bifurcation angle is the most consistent factor affecting the degree of both immediate and delayed angular remodeling.

\section{Statement of Ethics}

All procedures performed in studies involving human participants were in accordance with the ethical standards of the RUSH IRB Committee and the 1964 Helsinki Declaration and its later amendments or comparable ethical standards.

\section{Disclosure Statement}

Dr. Demetrius Lopes received research grants from Penumbra, Stryker, and Microvention, is a consultant/on the Advisory Board of Medtronic, Microvention, Asahi, and Siemens, and a principal investigator for Dawn, Swift Prime, and Therapy. Honoraria were granted by Stryker, Microvention, Medtronic, and Penumbra. Ownership interest/options were held by Crowdoptic, Three Rivers, Neurvana, MIVI, Blockade, NDI, Nextgen, Elum, and Bendit.

\section{References}

1 Beller E, Klopp D, Göttler J, Kaesmacher J, Zimmer C, Kirschke JS, et al. Closed-Cell Stent-Assisted Coiling of Intracranial Aneurysms: Evaluation of Changes in Vascular Geometry Using Digital Subtraction Angiography. PLoS One. 2016 Apr;11(4):e0153403.

2 Rayz VL, Boussel L, Ge L, Leach JR, Martin AJ, Lawton MT, et al. Flow residence time and regions of intraluminal thrombus deposition in intracranial aneurysms. Ann Biomed Eng. 2010 Oct;38(10):3058-69.

$3 \mathrm{Xu} \mathrm{J}, \mathrm{Wu}$ Z, Yu Y, Lv N, Wang S, Karmonik C, et al. Combined Effects of Flow Diverting Strategies and Parent Artery Curvature on Aneurysmal Hemodynamics: A CFD Study. PLoS One. 2015 Sep;10(9):e0138648.

4 Seshadhri S, Janiga G, Beuing 0, Skalej M, Thévenin D. Impact of stents and flow diverters on hemodynamics in idealized aneurysm models. J Biomech Eng. 2011 Jul;133(7):071005. 
5 Cho WS, Kang HS, Kim JE, Kwon OK, Oh CW, Cho YD, et al. Angle change of the parent arteries after stentassisted coil embolization of wide-necked intracranial bifurcation aneurysms. Clin Radiol. 2014 Feb; 69(2):e63-70.

6 Gao B, Baharoglu MI, Cohen AD, Malek AM. Stent-assisted coiling of intracranial bifurcation aneurysms leads to immediate and delayed intracranial vascular angle remodeling. AJNR Am J Neuroradiol. 2012 Apr;33(4): 649-54.

7 Gao B, Baharoglu MI, Malek AM. Angular remodeling in single stent-assisted coiling displaces and attenuates the flow impingement zone at the neck of intracranial bifurcation aneurysms. Neurosurgery. 2013 May; $72(5)$ : 739-48.

8 Huang QH, Wu YF, Xu Y, Hong B, Zhang L, Liu JM. Vascular geometry change because of endovascular stent placement for anterior communicating artery aneurysms. AJNR Am J Neuroradiol. 2011 Oct;32(9):1721-5.

9 Sağlam M, Kızılkılıç O, Anagnostakou V, Yıldız B, Koçer N, Işlak C. Geometrical characteristics after Y-stenting of the basilar bifurcation. Diagn Interv Radiol. 2015 Nov-Dec;21(6):483-7.

10 De Bock S, Iannaccone F, De Santis G, De Beule M, Mortier P, Verhegghe B, et al. Our capricious vessels: the influence of stent design and vessel geometry on the mechanics of intracranial aneurysm stent deployment. J Biomech. 2012 May;45(8):1353-9.

11 Piotin M, Blanc R. Balloons and stents in the endovascular treatment of cerebral aneurysms: vascular anatomy remodeled. Front Neurol. 2014 Apr;5:41. 